\title{
Short-Term Change of Handgrip Strength After Trigger Point Injection in Women With Muscular Pain in the Upper Extremities
}

\author{
Soo Jin Lee, MD, Dong Heun Ahn, MD, Ji Hun Jung, MD, Yong Rok Kim, MD, Young Jin Lee, MD \\ Department of Physical Medicine and Rehabilitation, Konyang University College of Medicine, Daejeon, Korea
}

\begin{abstract}
Objective To determine overall handgrip strength (HGS), we assessed the short-term change of HGS after trigger point injection (TPI) in women with muscular pain in the upper extremities by comparison with established pain scales.

Methods The study enrolled 50 female patients (FMS with MPS group: 29 patients with combined fibromyalgia [FMS] and myofascial pain syndrome [MPS]; MPS group: 21 patients with MPS) who presented with muscular pain in the upper extremities at Konyang University Hospital. In addition, a total of 9 healthy women (control group) were prospectively enrolled in the study. We surveyed the three groups using the following established pain scales: the Fibromyalgia Impact Questionnaire (FIQ), the 36-Item Short Form Health Survey (SF-36), and the Short Form McGill Pain Questionnaire (MPQ). HGS was measured in both hands of study participants using a handgrip dynamometer. We performed TPI ( $0.5 \%$ lidocaine, total $10 \mathrm{~mL}$, injected at the pain site of upper extremities). After 20 minutes, we remeasured the patient's HGS and MPQ score.

Results ANOVA analysis was conducted among groups. Based on Tukey multiple comparison test, the majority of FIQ and SF-36 subscales, total FIQ and SF-36 scores, MPQ and HGS were significantly different between FMS with MPS and the other groups. There was no statistically significant difference between MPS and control groups. Higher HGS was positively associated with enhanced physical function, negatively associated with total FIQ and MPQ scores, and positively associated with the total SF-36 score calculated using Spearman correlation. Post-TPI MPQ decreased and HGS increased. In patient groups, a negative correlation was found between MPQ and HGS. Conclusion The HGS test might potentially be a complementary tool in assessing the short-term treatment effects of women with muscular pain in the upper extremities.
\end{abstract}

Keywords Fibromyalgia, Hand strength, Trigger point injection

Received September 3, 2013; Accepted October 16, 2013

Corresponding author: Young Jin Lee

Department of Physical Medicine and Rehabilitation, Konyang University College of Medicine, 158 Gwanjeodong-ro, Seo-gu, Daejeon 302-718, Korea Tel: +82-42-600-6700, Fax: +82-42-600-9090, E-mail: eutravel@kyuh.ac.kr

(c) This is an open-access article distributed under the terms of the Creative Commons Attribution Non-Commercial License (http://creativecommons.org/ licenses/by-nc/3.0) which permits unrestricted noncommercial use, distribution, and reproduction in any medium, provided the original work is properly cited. Copyright $\odot 2014$ by Korean Academy of Rehabilitation Medicine 


\section{INTRODUCDION}

The clinical characteristics of patients with fibromyalgia (FMS) are complex and include chronic pain and its associated symptoms: insomnia, fatigue, stiffness, anxiety, depression, multiple sensitive and tender areas, and morning tiredness [1-7]. The assessment and monitoring of FMS is a dynamic process [8]. There is no single test that can diagnose FMS; there is currently a debate over what should be considered essential diagnostic criteria and whether an objective diagnosis is even possible with the disease [9].

The handgrip strength (HGS) test is a complementary evaluation tool in myriad different conditions, such as malnourished preoperative colorectal cancer patients, prostate cancer patients, breast cancer survivors, diabetics, chronic peritoneal dialysis, congestive heart failure, survivors of critical illness, and FMS [1,7,10-16]. Patients with FMS generally have demonstrated lower levels of HGS [10,17-21]. The HGS test might have clinical utility to discriminate between the presence and absence of FMS, as well as moderate and severe cases of FMS in women [10].

The aforementioned studies assessed whether the HGS test measures the effects of treatment or assesses physical function in other musculoskeletal disorders, particularly myofascial pain syndrome (MPS).

Patients with FMS have diffuse musculoskeletal pain and multiple tender points [11]. Unlike FMS, muscle pain in MPS is usually local or regional pain due to trigger point in a taut band of skeletal muscle fibers [22]. Although non-pharmacological modalities, such as stretching exercises, mechanical massage, hot pack, ultrasound, electrical stimulation, etc., may be common to both conditions, the pharmacological management of FMS and MPS differ [23]. The origin of pain in MPS is purportedly peripheral in origin; thus, nonsteroidal antiinflammatory drugs are effective on peripheral pain. In contrast, pain in FMS is supposed to be central in origin; thus, antidepressant, antiepileptic drugs and a variety of neuroactive compounds are available for FMS [23]. Trigger point injections (TPI) are commonly used to relieve pain for patients with MPS [22]. Administering TPI in patients with MPS results in immediate and effective pain relief [22]. Some patients with FMS also have MPS with active trigger points that contribute to their pain [22]. The aim of this study is to determine the potential of the HGS test for assessing short-term treatment effects of patients with muscular pain in the upper extremities, and to delineate the difference between FMS in the MPS group and uncomplicated MPS group with the effect of TPI.

\section{MATERIALS AND METHODS}

The study enrolled a total of fifty women (FMS with MPS group: 29 patients with combined FMS and MPS; MPS group: 21 patients with just MPS) who presented with muscular pain in the upper extremities at Konyang University Hospital. A total of nine healthy women (control group) were prospectively enrolled between July and October 2011.

A rheumatologist at Konyang University Hospital confirmed the diagnosis of patients with combined FMS and MPS. The criteria of the American College of Rheumatology were adopted for the diagnosis of FMS [9]: widespread pain in at least three of the four body quadrants for at least three months and localized pain on palpation in at least 11 of 18 selected muscle-tendon junctions or tender points [9]. The selected tender points for examination (all bilateral) included: occiput, low cervical spine, trapezius and supraspinatus muscles, second rib, lateral epicondyle of elbow, gluteal muscle, greater trochanter, and knee [9]. Among the patients who were initially diagnosed with FMS, if they also had trigger points in upper extremities, the patients were recruited into the FMS with MPS group. Patients with muscular pain in the upper extremities were referred to the outpatient clinic of the Department of Physical Medicine and Rehabilitation; they were ultimately enrolled in the MPS group. Subjects with a history of surgery (including amputation) of the upper extremities, other rheumatic disease, or severe somatic or psychiatric disorders were excluded from the study.

The study design is displayed in Fig. 1. All participants were evaluated using the following established pain scales at baseline: the Korean version of the Fibromyalgia Impact Questionnaire (FIQ), the Korean version of the 36-Item Short Form Health Survey (SF-36), and the Korean version of the Short Form McGill Pain Questionnaire (MPQ). HGS was measured in all groups at baseline.

FIQ was designed to measure aspects of health believed to be most affected by FMS [24]; it was used in this study to evaluate the health status of subjects for intergroup 
comparison. The scale contains a total of 10 items with a score range of each item from 0 to 10 ; thus, the maximum possible score is 100 . A higher FIQ score indicates an increased severity of FMS.

The health-related quality of life (HRQOL) was assessed by SF-36 [25], which has a total of 36 items scored on a scale from 0 to 100. A higher SF-36 score indicates better HRQOL.

MPQ was used to assess pain severity and its characteristics; the scale includes 11 sensory and four affective parameters of pain experience, with each question graded from 0 to 3 . The persistent pain intensity (range $0-5$ ) and visual analog scale were also included to provide overall intensity scores. The range of possible MPQ scores is from 0 to 60 , with higher scores indicating greater intensity of pain.

HGS was measured with a Jamar hydraulic hand dynamometer (Sammons Preston, Warrenville, IL, USA; Fig. 2) held in either hand for at least 2 seconds, with the arm fully extended at an angle of $30^{\circ}$ with respect to the trunk and the palm of the hand perpendicular to the shoulder line [10]. The mean score of strength in both hands was recorded. Handgrip span was calculated using the formula suggested by Ruiz et al. [10,27]:

handgrip span=hand size $/(5+1.5)$.

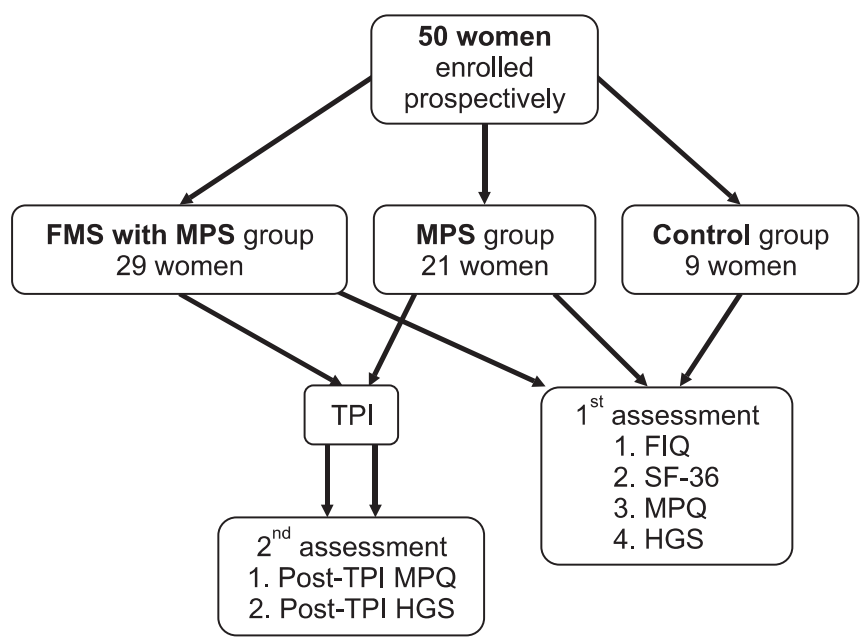

Fig. 1. Flowchart of the study. FMS, fibromyalgia; MPS, myofascial pain syndrome; TPI, trigger point injection; FIQ, Korean version of Fibromyalgia Impact Questionnaire; SF-36, Korean version of 36-Item Short Form Health Survey; MPQ, Korean version of Short Form McGill Pain Questionnaire; HGS, handgrip strength.
We selected TPI as the method of treatment that is commonly used to relieve pain in MPS. Patients in the FMS with MPS and MPS groups received TPI treatment $(0.5 \%$ lidocaine, total $10 \mathrm{~mL}$, injected at the pain site in the upper extremities). Twenty minutes after TPI, HGS was remeasured and the MPQ scoring was recorded.

The measurement of HGS and TPI were administered by two physicians in the Department of Physical Medicine and Rehabilitation. All subjects received oral and written information about the study protocol and signed informed consent before participation.

The statistical analytical software package SPSS ver. 18.0 for Windows (SPSS Inc., Chicago, IL, USA) was used. Baseline demographic characteristics, FIQ, SF-36 scores, the MPQ score, and HGS, were analyzed using ANOVA. Spearman correlation coefficients were used to examine the association between study participant's HGS and FIQ, SF-36, and MPQ scoring. MPQ and HGS were used to assess TPI effects, which were evaluated using a paired t-test. The association between MPQ and HGS was assessed by Spearman correlation: a correlation measure of 0-0.25 indicates an absent or weak linear relationship; a correlation measure of $0.25-0.50$ indicates a moderate linear relationship; a correlation measure of 0.50-0.75 indicates a moderate to good linear relationship; and a correlation greater than 0.75 indicates a very good linear relationship [26]. Data are presented as mean \pm standard deviation. Statistical significance was assigned at a pvalue less than $5 \%(\mathrm{p}<0.05)$.

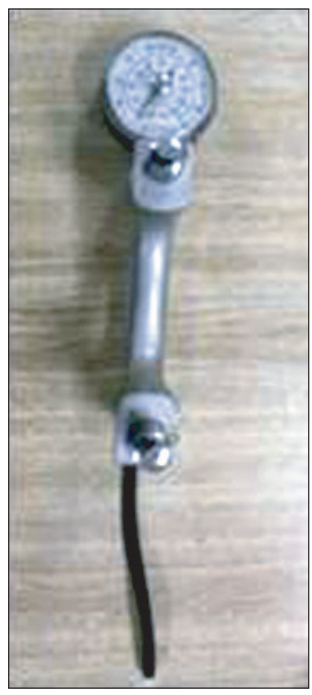

Fig. 2. Hand dynamometer. 


\section{RESULTS}

Fifty patients and nine healthy women were enrolled in the study; because very few men suffer from FMS, only women were enrolled in this study (Fig. 1).

Table 1 shows the baseline characteristics of study participants in the areas of HGS, FIQ, SF-36, and MPQ. The FMS with MPS group (age, 47.18 \pm 9.36 years) was younger than the other two groups (MPS 56.81 \pm 6.68 , control $55.89 \pm 7.87 ; \mathrm{p}=0.00)$. Height, weight, body mass index, and handgrip span showed no significant differences at baseline. Mean HGS showed a significant difference in all groups $(13.34 \pm 5.20,18.55 \pm 6.44$, and $20.17 \pm 2.66 \mathrm{~kg}$ in FMS with MPS, MPS, and control, respectively; $\mathrm{p}=0.001$ ). Apart from the "Physical impairment" FIQ subscale and "Mental health" of the SF-36 subscale, most scores for FIQ, SF36, and MPQ showed statistically significant differences $(\mathrm{p}<0.05)$.

Intergroup differences were determined by using Tukey multiple comparison test. Most FIQ and SF-36 subscales,

Table 1. Baseline characteristics, handgrip strength, FIQ, SF-36, and MPQ in the three groups ( $\mathrm{n}=59$ )

\begin{tabular}{|c|c|c|c|c|}
\hline Characteristic & FMS with MPS $(n=29)$ & MPS $(n=21)$ & Control $(n=9)$ & p-value \\
\hline Age (yr) & $47.18 \pm 9.36^{\mathrm{a}}$ & $56.81 \pm 6.68^{\mathrm{b}, \mathrm{c}}$ & $55.89 \pm 7.87^{\mathrm{b}, \mathrm{c}}$ & $0.000^{*}$ \\
\hline Height $(\mathrm{cm})$ & $157.86 \pm 6.14^{\mathrm{a}, \mathrm{b}, \mathrm{c}}$ & $157.14 \pm 4.90^{\mathrm{a}, \mathrm{b}, \mathrm{c}}$ & $155.00 \pm 4.92^{\mathrm{a}, \mathrm{b}, \mathrm{c}}$ & 0.411 \\
\hline Weight (kg) & $57.39 \pm 8.92^{\mathrm{a}, \mathrm{b}, \mathrm{c}}$ & $60.95 \pm 6.42^{\mathrm{a}, \mathrm{b}, \mathrm{c}}$ & $60.89 \pm 8.89^{\mathrm{a}, \mathrm{b}, \mathrm{c}}$ & 0.259 \\
\hline BMI $\left(\mathrm{kg} / \mathrm{m}^{2}\right)$ & $23.22 \pm 4.68^{a, b, c}$ & $24.65 \pm 1.94^{\mathrm{a}, \mathrm{b}, \mathrm{c}}$ & $25.29 \pm 3.23^{a, b, c}$ & 0.233 \\
\hline HGS (kg) & $13.34 \pm 5.20^{\mathrm{a}}$ & $18.55 \pm 6.44^{\mathrm{b}, \mathrm{c}}$ & $20.17 \pm 2.66^{\mathrm{b}, \mathrm{c}}$ & $0.001^{*}$ \\
\hline Handgrip span (cm) & $4.97 \pm 0.21^{\mathrm{a}, \mathrm{b}, \mathrm{c}}$ & $5.01 \pm 0.12^{\mathrm{a}, \mathrm{b}, \mathrm{c}}$ & $4.98 \pm 0.33^{\mathrm{a}, \mathrm{b}, \mathrm{c}}$ & 0.214 \\
\hline FIQ & $76.34 \pm 20.15^{\mathrm{a}}$ & $51.30 \pm 18.67^{\mathrm{b}}$ & $30.72 \pm 16.36^{c}$ & $0.000^{*}$ \\
\hline Physical impairment & $18.36 \pm 8.02^{\mathrm{a}, \mathrm{b}, \mathrm{c}}$ & $17.67 \pm 7.25^{\mathrm{a}, \mathrm{b}, \mathrm{c}}$ & $12.56 \pm 7.99^{\mathrm{a}, \mathrm{b}, \mathrm{c}}$ & 0.149 \\
\hline Feeling good & $4.46 \pm 1.79^{\mathrm{a}}$ & $3.00 \pm 1.48^{\mathrm{b}, \mathrm{c}}$ & $1.67 \pm 1.32^{\mathrm{b}, \mathrm{c}}$ & $0.000^{*}$ \\
\hline Unable to work & $4.29 \pm 2.31^{\mathrm{a}}$ & $1.19 \pm 1.29^{\mathrm{b}, \mathrm{c}}$ & $0.11 \pm 0.33^{\mathrm{b}, \mathrm{c}}$ & $0.000^{*}$ \\
\hline Able to work & $7.25 \pm 2.62^{\mathrm{a}}$ & $4.19 \pm 2.50^{\mathrm{b}, \mathrm{c}}$ & $2.00 \pm 1.44^{\mathrm{b}, \mathrm{c}}$ & $0.000^{*}$ \\
\hline Pain & $7.39 \pm 2.53^{\mathrm{a}}$ & $3.86 \pm 2.74^{\mathrm{b}, \mathrm{c}}$ & $2.17 \pm 1.75^{\mathrm{b}, \mathrm{c}}$ & $0.000^{*}$ \\
\hline Fatigue & $7.39 \pm 2.47^{\mathrm{a}}$ & $5.31 \pm 2.80^{\mathrm{b}, \mathrm{c}}$ & $3.72 \pm 1.94^{\mathrm{b}, \mathrm{c}}$ & $0.001^{*}$ \\
\hline Rested & $7.64 \pm 2.93^{\mathrm{a}}$ & $3.86 \pm 2.74^{\mathrm{b}, \mathrm{c}}$ & $3.61 \pm 2.70^{\mathrm{b}, \mathrm{c}}$ & $0.000^{*}$ \\
\hline Stiffness & $7.11 \pm 2.73^{\mathrm{a}}$ & $4.79 \pm 3.08^{\mathrm{b}, \mathrm{c}}$ & $3.83 \pm 2.80^{\mathrm{b}, \mathrm{c}}$ & $0.003^{*}$ \\
\hline Anxiety & $6.38 \pm 3.09^{\mathrm{a}}$ & $4.01 \pm 2.97^{\mathrm{b}, \mathrm{c}}$ & $3.39 \pm 2.86^{\mathrm{b}, \mathrm{c}}$ & $0.008^{*}$ \\
\hline Depression & $6.07 \pm 2.91^{\mathrm{a}}$ & $3.43 \pm 2.65^{\mathrm{b}, \mathrm{c}}$ & $1.39 \pm 1.71^{\mathrm{b}, \mathrm{c}}$ & $0.000^{*}$ \\
\hline SF-36 & $1011.43 \pm 468.18^{\mathrm{a}}$ & $1925.05 \pm 856.93^{\mathrm{b}, \mathrm{c}}$ & $2491.67 \pm 442.65^{\mathrm{b}, \mathrm{c}}$ & $0.000^{*}$ \\
\hline Physical functioning & $380.36 \pm 198.30^{\mathrm{a}}$ & $654.76 \pm 196.79^{\mathrm{b}, \mathrm{c}}$ & $705.56 \pm 192.75^{\mathrm{b}, \mathrm{c}}$ & $0.000^{*}$ \\
\hline Emotional role & $53.57 \pm 103.57^{\mathrm{a}}$ & $180.95 \pm 147.03^{\mathrm{b}, \mathrm{c}}$ & $266.67 \pm 150.00^{\mathrm{b}, \mathrm{c}}$ & $0.000^{*}$ \\
\hline Physical role & $53.57 \pm 103.57^{\mathrm{a}}$ & $133.33 \pm 119.72^{\mathrm{a}, \mathrm{b}}$ & $211.11 \pm 105.41^{\mathrm{b}}$ & $0.001^{*}$ \\
\hline Energy/fatigue & $80.36 \pm 85.89^{\mathrm{a}}$ & $154.76 \pm 82.01^{\mathrm{b}}$ & $261.11 \pm 45.26^{\mathrm{c}}$ & $0.000^{*}$ \\
\hline Mental health & $208.04 \pm 114.27^{\mathrm{a}, \mathrm{b}, \mathrm{c}}$ & $434.57 \pm 655.12^{\mathrm{a}, \mathrm{b}, \mathrm{c}}$ & $388.89 \pm 90.24^{\mathrm{a}, \mathrm{b}, \mathrm{c}}$ & 0.139 \\
\hline Social functioning & $66.07 \pm 40.95^{\mathrm{a}}$ & $139.29 \pm 83.13^{\mathrm{b}, \mathrm{c}}$ & $163.89 \pm 43.50^{\mathrm{b}, \mathrm{c}}$ & $0.000^{*}$ \\
\hline Pain & $48.93 \pm 44.87^{\mathrm{a}}$ & $117.86 \pm 48.83^{\mathrm{b}, \mathrm{c}}$ & $133.33 \pm 43.30^{\mathrm{b}, \mathrm{c}}$ & $0.000^{*}$ \\
\hline General health & $121.43 \pm 85.18^{\mathrm{a}}$ & $223.81 \pm 79.64^{\mathrm{b}}$ & $361.11 \pm 67.44^{\mathrm{c}}$ & $0.000^{*}$ \\
\hline MPQ & $34.88 \pm 14.04^{\mathrm{a}}$ & $18.24 \pm 9.94^{\mathrm{b}}$ & $5.60 \pm 0.69^{c}$ & $0.000 *$ \\
\hline
\end{tabular}

Values are presented as mean \pm standard deviation.

FIQ, Korean version of Fibromyalgia Impact Questionnaire; SF-36, Korean version of 36-Item Short Form Health Survey; MPQ, Korean version of Short Form McGill Pain Questionnaire; FMS, fibromyalgia; MPS, myofascial pain syndrome; BMI, body mass index; HGS, handgrip strength.

${ }^{*} \mathrm{p}<0.05$, significantly different according to ANOVA. The same letters indicate non-significant difference between groups based on Tukey multiple comparison test. 
total FIQ and SF-36 scores, MPQ, and HGS showed statistically significant differences between the FMS with MPS group and the other two groups $(\mathrm{p}<0.01)$; however, there were no statistically significant differences between the MPS and control groups ( $\mathrm{p}>0.05)$.

HGS was associated with an increase in overall physical function (Table 2). HGS was negatively associated with FIQ and MPQ; HGS was positively associated with SF-36 citing Spearman correlation. This association was statistically significant apart from certain subscales, such as "Feel good" (FIQ) and "Mental health" (SF-36).

Most FIQ subscales including "Physical impairment," "Unable to work," "Able to work," "Pain," "Fatigue," "Resting," "Stiffness," "Anxiety," and total FIQ score showed a moderately negative correlation with HGS $(r<-0.3$,

Table 2. Correlation between handgrip strength and FIQ, SF-36, and MPQ in the three groups

\begin{tabular}{|lcc}
\hline \multicolumn{1}{c}{ Variable } & r & p-value \\
\hline FIQ & -0.528 & $0.000^{*}$ \\
Physical impairment & -0.336 & $0.010^{*}$ \\
\hline Feeling good & -0.170 & 0.201 \\
\hline Unable to work & -0.534 & 0.000 \\
\hline Able to work & -0.471 & $0.000^{*}$ \\
\hline Pain & -0.484 & $0.000^{*}$ \\
\hline Fatigue & -0.399 & $0.002^{*}$ \\
\hline Resting & -0.407 & $0.002^{*}$ \\
\hline Stiffness & -0.480 & $0.000^{*}$ \\
\hline Anxiety & -0.300 & $0.022^{*}$ \\
\hline Depression & -0.261 & $0.047^{*}$ \\
\hline SF-36 & 0.407 & $0.002^{*}$ \\
\hline Physical functioning & 0.396 & $0.002^{*}$ \\
\hline Emotional role & 0.359 & $0.006^{*}$ \\
\hline Physical role & 0.281 & $0.032^{*}$ \\
\hline Energy/fatigue & 0.484 & $0.000^{*}$ \\
\hline Mental health & 0.210 & 0.113 \\
\hline Social functioning & 0.394 & $0.002^{*}$ \\
\hline Pain & 0.527 & $0.000^{*}$ \\
\hline General health & 0.408 & $0.001^{*}$ \\
\hline MPQ & -0.464 & $0.000^{*}$ \\
\hline
\end{tabular}

FIQ, Korean version of Fibromyalgia Impact Questionnaire; SF-36, Korean version of 36-Item Short Form Health Survey; MPQ, Korean version of Short Form McGill Pain Questionnaire.

${ }^{*} \mathrm{p}<0.05$, significantly different according to Spearman correlation. $\mathrm{p}<0.05)$. The FIQ subscale "Depression" had a weak, negative association with HGS ( $\mathrm{r}=-0.261, \mathrm{p}=0.047)$. Most SF-36 subscales had a moderately positive association $(\mathrm{r}>0.3, \mathrm{p}<0.05)$. Only the subscale "Physical role" in SF36 was weakly associated with HGS ( $\mathrm{r}=0.281, \mathrm{p}=0.032)$, whereas MPQ had a clear negative association $(r=-0.464$, $\mathrm{p}=0.000$ ).

The effects of TPI on the patient groups are shown in Table 3: post-TPI MPQ decreased and HGS increased. In the patient groups FMS with MPS and MPS, a statisti-

Table 3. Effects of TPI

\begin{tabular}{llll}
\hline \multicolumn{1}{c}{ Variable } & \multicolumn{1}{c}{ Pre-TPI } & \multicolumn{1}{c}{ Post-TPI } & p-value \\
\hline FMS with MPS + MPS & & & \\
MPQ & $27.75 \pm 14.87$ & $16.57 \pm 10.55$ & $0.000^{*}$ \\
$\quad$ HGS & $15.57 \pm 6.27$ & $16.51 \pm 6.20$ & $0.000^{*}$ \\
FMS with MPS & & & \\
MPQ & $34.88 \pm 14.04$ & $20.20 \pm 11.64$ & $0.009^{*}$ \\
HGS & $13.34 \pm 5.20$ & $14.34 \pm 5.54$ & $0.000^{*}$ \\
MPS & & & \\
MPQ & $18.24 \pm 9.94$ & $11.74 \pm 6.43$ & $0.019^{*}$ \\
HGS & $18.55 \pm 6.44$ & $19.41 \pm 5.96$ & $0.000^{*}$ \\
\hline
\end{tabular}

TPI, trigger point injection; FMS, fibromyalgia; MPS, myofascial pain syndrome; MPQ, Korean version of Short Form McGill Pain Questionnaire; HGS, handgrip strength.

${ }^{*} \mathrm{p}<0.05$, significantly different according to paired t-test.

Table 4. Correlation between MPQ and HGS

\begin{tabular}{lll}
\hline \multicolumn{1}{c}{ Variable } & r & p-value \\
\hline FMS with MPS + MPS & & \\
\hline Between pre-TPI MPQ and pre-TPI HGS & -0.402 & $0.004^{*}$ \\
Between post-TPI MPQ and post-TPI HGS & -0.305 & $0.033^{*}$ \\
FMS with MPS & & \\
Between pre-TPI MPQ and pre-TPI HGS & -0.138 & 0.483 \\
Between post-TPI MPQ and post-TPI HGS & -0.170 & 0.387 \\
MPS & & \\
\hline Between pre-TPI MPQ and pre-TPI HGS & -0.491 & $0.024^{*}$ \\
Between post-TPI MPQ and post-TPI HGS & -0.295 & 0.194 \\
\hline
\end{tabular}

MPQ, Korean version of Short Form McGill Pain Questionnaire; HGS, handgrip strength; FMS, fibromyalgia; MPS, myofascial pain syndrome; TPI, trigger point injection.

${ }^{*} \mathrm{p}<0.05$, significantly different according to Spearman correlation. 
cally significant difference was found between both preand post-TPI MPQ and HGS (both $\mathrm{p}=0.00$ ). Between the pre-TPI HGS and post-TPI HGS in patient group had a significant difference $(\mathrm{p}=0.00)$ in patient group. In FMS with MPS group and the MPS group, these relationships were maintained $(\mathrm{p}<0.02)$. The MPQ and HGS score were different in each group, but the pre/post-TPI difference values were similar in each group. HGS reflected the effect of TPI in all 3 groups: FMS with MPS + MPS group, FMS with MPS group, and the MPS group.

Table 4 displays the correlations between MPQ and HGS, which were negative and moderate in the two patient groups $(\mathrm{r}<-0.3, \mathrm{p}<0.01)$; this relationship was maintained post-TPI. No statistically significant correlation was found for the FMS with MPS group between MPQ and HGS ( $p>0.05)$. Correlation between pre-TPI MPQ and HGS in the MPS group was significant $(\mathrm{r}=-0.491$, $\mathrm{p}=0.024$ ). Post-TPI, the correlation between these two factors was not significant ( $\mathrm{p}=0.194)$ in the MPS group. The correlation between MPQ and HGS is stronger in the MPS group than FMS with MPS group.

\section{DISCUSSION}

The study found that HGS was reduced according to an increase in the pain scales used in this study, and reflected the effects of TPI. Therefore, HGS might be a complementary tool for assessment of short-term treatment effects.

Despite the fact that patients in the FMS with MPS group were younger than those in the other groups at baseline, HGS in the FMS with MPS group was still the lowest. In previous studies, HGS in women with FMS was lower than that in age-matched healthy women $[10,11]$. According to Panton et al. [11], older women without FMS (mean age $71 \pm 7$ years) had poorer HGS than women with FMS (mean age $46 \pm 7$ years). The results of the present study counter those of previous studies $[10,11]$, and establishment of a more robust correlation between physical function of the subjects and HGS will be possible through an age-matched study, which probably involves dividing the FMS with MPS group into different age groups (e.g., 20-30 and 31-40 years).

In a recent study [27], the average FIQ score of patients with FMS was approximately 50, whereas that of severely afflicted patients was generally $>70$. In our study, the mean total FIQ scores in the FMS with MPS and MPS groups were $76.34 \pm 20.15$ and $51.30 \pm 18.67$, respectively. In our study, the FMS with MPS group falls under the severe FMS which were designated by FIQ score in the previous study and the MPS group also falls under the FMS [10]. More women with severe FMS were compelled to participate in the study because subjects in the patient group were recruited from Konyang University Hospital. Furthermore, it was able to suggest that the MPS group in our study involved FMS patients.

Overall HGS in this study was found to be poorer than that in previous studies $[1,10,11,28]$. The mean HGS in middle-aged Korean women is about $23.5 \mathrm{~kg}$ [28]. The main mitigating factor in this study maybe subject enrollment: our study involved more severely affected patients recruited from a hospital. It should be noted, however, that the HGS of the control group was also lower than the mean value found in other studies. Furthermore, a large number of cases are needed to investigate the correct population mean for establishing HGS in each group.

Post-TPI HGS increased and MPQ decreased, supporting the hypothesis that pain has a major impact on patients' handgrip strength. The pre/post-TPI difference of HGS is similar in each group. The TPI effect of the patients with an MPS component might be evaluated by measuring handgrip strength.

HGS can reflect the effects of treatment as measured by MPQ, and both MPQ and HGS showed a moderately negative correlation pre/post-TPI in the patient group. HGS had significant reflectivity of TPI effect similar to MPQ. The resulting correlation between MPQ and HGS in each of the two groups: the FMS with MPS group and the MPS group, no statistically significant difference was observed compared with the patient group (FMS with MPS + MPS group). This may be the result of a small number of subjects (sample size) in each of the two groups. Negative correlation between two factors was preserved in each of the two groups.

This study has several limitations. First, we assessed the effect of treatment by measuring MPQ and HGS about 20 minutes after administering TPI. These scores reflect only the immediate effect of treatment. Further study assessing long-term effects will be needed. The number of subjects included for analysis was relatively small, although a larger number of subjects were assessed for eligibility. The mean value of age-specific HGS in each 
group should be investigated, but our Institutional Review Board disapproved of this strategy.

In conclusion, women with severe pain in their upper extremities had poorer handgrip strength. Compared with established pain scales, the HGS test was not inferior. Post-TPI HGS increased and MPQ decreased. HGS test might be a complementary tool in assessing the shortterm treatment effects of women with muscular pain in the upper extremities. In this study, subjects were not enrolled in large numbers; thus, a large prospective study is needed.

\section{CONFLICT OF INTEREST}

No potential conflict of interest relevant to this article was reported.

\section{ACKNOWLEDGMENTS}

We thank all participants. as well as Professor Chung-Il Jung and Mi-Hae Kwon from the Department of Rheumatology of Konyang University Hospital.

\section{REFERENCES}

1. Cantarero-Villanueva I, Fernandez-Lao C, DiazRodriguez L, Fernandez-de-Las-Penas C, Ruiz JR, Arroyo-Morales $\mathrm{M}$. The handgrip strength test as a measure of function in breast cancer survivors: relationship to cancer-related symptoms and physical and physiologic parameters. Am J Phys Med Rehabil 2012;91:774-82.

2. Markes M, Brockow T, Resch KL. Exercise for women receiving adjuvant therapy for breast cancer. Cochrane Database Syst Rev 2006;(4):CD005001.

3. Mortimer JE, Barsevick AM, Bennett CL, Berger AM, Cleeland C, DeVader SR, et al. Studying cancer-related fatigue: report of the NCCN scientific research committee. J Natl Compr Canc Netw 2010;8:1331-9.

4. Bower JE, Ganz PA, Desmond KA, Rowland JH, Meyerowitz BE, Belin TR. Fatigue in breast cancer survivors: occurrence, correlates, and impact on quality of life. J Clin Oncol 2000;18:743-53.

5. Lee ES, Lee MK, Kim SH, Ro JS, Kang HS, Kim SW, et al. Health-related quality of life in survivors with breast cancer 1 year after diagnosis compared with the general population: a prospective cohort study. Ann Surg 2011;253:101-8.

6. al-Majid S, McCarthy DO. Cancer-induced fatigue and skeletal muscle wasting: the role of exercise. Biol Res Nurs 2001;2:186-97.

7. Burden ST, Hill J, Shaffer JL, Todd C. Nutritional status of preoperative colorectal cancer patients. J Hum Nutr Diet 2010;23:402-7.

8. Wolfe F, Clauw DJ, Fitzcharles MA, Goldenberg DL, Katz RS, Mease P, et al. The American College of Rheumatology preliminary diagnostic criteria for fibromyalgia and measurement of symptom severity. Arthritis Care Res (Hoboken) 2010;62:600-10.

9. Wolfe F, Smythe HA, Yunus MB, Bennett RM, Bombardier C, Goldenberg DL, et al. The American College of Rheumatology 1990 Criteria for the classification of fibromyalgia: report of the multicenter criteria committee. Arthritis Rheum 1990;33:160-72.

10. Aparicio VA, Ortega FB, Heredia JM, Carbonell-Baeza A, Sjostrom M, Delgado-Fernandez M. Handgrip strength test as a complementary tool in the assessment of fibromyalgia severity in women. Arch Phys Med Rehabil 2011;92:83-8.

11. Panton LB, Kingsley JD, Toole T, Cress ME, Abboud G, Sirithienthad P, et al. A comparison of physical functional performance and strength in women with fibromyalgia, age- and weight-matched controls, and older women who are healthy. Phys Ther 2006;86:1479-88.

12. Soyupek F, Soyupek S, Perk H, Ozorak A. Androgen deprivation therapy for prostate cancer: effects on hand function. Urol Oncol 2008;26:141-6.

13. Kaya T, Karatepe AG, Gunaydn R, Yetis H, Uslu A. Disability and health-related quality of life after breast cancer surgery: relation to impairments. South Med J 2010;103:37-41.

14. van Sloten TT, Savelberg HH, Duimel-Peeters IG, Meijer K, Henry RM, Stehouwer CD, et al. Peripheral neuropathy, decreased muscle strength and obesity are strongly associated with walking in persons with type 2 diabetes without manifest mobility limitations. Diabetes Res Clin Pract 2011;91:32-9.

15. Wang AY, Sanderson JE, Sea MM, Wang M, Lam CW, Chan IH, et al. Handgrip strength, but not other nutrition parameters, predicts circulatory congestion in peritoneal dialysis patients. Nephrol Dial Transplant 2010;25:3372-9. 
16. Ali NA, O’Brien JM Jr, Hoffmann SP, Phillips G, Garland A, Finley JC, et al. Acquired weakness, handgrip strength, and mortality in critically ill patients. Am J Respir Crit Care Med 2008;178:261-8.

17. Nordenskiold UM, Grimby G. Grip force in patients with rheumatoid arthritis and fibromyalgia and in healthy subjects: a study with the Grippit instrument. Scand J Rheumatol 1993;22:14-9.

18. Sahin G, Ulubas B, Calikoglu M, Erdogan C. Handgrip strength, pulmonary function tests, and pulmonary muscle strength in fibromyalgia syndrome: is there any relationship? South Med J 2004;97:25-9.

19. Maquet D, Croisier JL, Renard C, Crielaard JM. Muscle performance in patients with fibromyalgia. Joint Bone Spine 2002;69:293-9.

20. Mengshoel AM, Forre O, Komnaes HB. Muscle strength and aerobic capacity in primary fibromyalgia. Clin Exp Rheumatol 1990;8:475-9.

21. Dombernowsky T, Dreyer L, Bartels EM, DanneskioldSamsoe B. Muscular strength in patients with fibromyalgia: a literature review. Ugeskr Laeger 2008;170:21724.
22. Hong CZ, Hsueh TC. Difference in pain relief after trigger point injections in myofascial pain patients with and without fibromyalgia. Arch Phys Med Rehabil 1996;77:1161-6.

23. Chandola HC, Chakraborty A. Fibromyalgia and myofascial pain syndrome: a dilemma. Indian J Anaesth 2009;53:575-81.

24. Burckhardt CS, Clark SR, Bennett RM. The fibromyalgia impact questionnaire: development and validation. J Rheumatol 1991;18:728-33.

25. Han CW, Lee EJ, Iwaya T, Kataoka H, Kohzuki M. Development of the Korean version of Short-Form 36Item Health Survey: health related QOL of healthy elderly people and elderly patients in Korea. Tohoku J Exp Med 2004;203:189-94.

26. Colton T. Statistics in medicine. Clin Chem 1975;21: 789-90.

27. Ruiz-Ruiz J, Mesa JL, Gutierrez A, Castillo MJ. Hand size influences optimal grip span in women but not in men. J Hand Surg Am 2002;27:897-901.

28. Ko BK. The national physical fitness survey. Sejong: Korea Ministry of Culture, Sports and Tourism; 2011. 